PUPIL: International Journal of Teaching, Education and Learning

ISSN 2457-0648

Teodora Mabulay Salubayba, 2022

Volume 5 Issue 3, pp. 254-272

Received: 11 th September, 2021

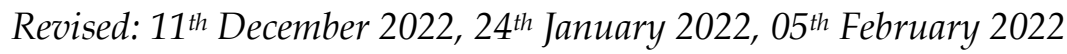

Accepted: 09th February 2022

Date of Publication: 23 ${ }^{\text {rd }}$ February 2022

DOI-https://doi.org/10.20319/pijtel.2022.53.254272

This paper can be cited as: Salubayba, T. M. (2022). Psychometric Properties of the Scale: My Online Teacher during a Pandemic. PUPIL: International Journal of Teaching, Education and Learning, 5(3), 254272.

This work is licensed under the Creative Commons Attribution-NonCommercial 4.0 International License. To view a copy of this license, visit http://creativecommons.org/licenses/by-nc/4.0/ or send a letter to Creative Commons, PO Box 1866, Mountain View, CA 94042, USA.

\title{
PSYCHOMETRIC PROPERTIES OF THE SCALE: MY ONLINE TEACHER DURING A PANDEMIC
}

\author{
Teodora Mabulay Salubayba \\ PhD, Assistant Professor, Educational Research and Evaluation, College of Education, \\ University of Philippines Diliman, Quezon City, Philippines \\ tmsalubayba@up.edu.ph \\ adorysalubayba@gmail.com
}

\begin{abstract}
Surveys regarding digital online learning during the Covid-19 pandemic that proliferated on the internet utilized online instruments that are mostly open-ended questions and closed forms with insufficient reliability and validity evidence provided. Instrument technical adequacy is crucial in any research endeavor to warrant the trustworthiness of research conclusions. This study describes the development of an instrument to measure students' observations of their online teachers during a pandemic. The 33-item instrument based on the responses to the open-ended online survey revealed acceptable internal consistency. The principal component analysis generated three subscales like personal traits and characteristics, classroom management skills and behavior, and communication and connectedness. Multiple comparisons discovered similarities and differences among the scores of the junior secondary, senior secondary, and college students across subscales. Subgroups like female and male students were compared that
\end{abstract}


showed no significant difference in the subscales. Likewise, students in the public and private schools were significantly different in subscale 2 but not significantly different in the other subscales. The scale that was developed conjures the importance of research instruments' technical adequacy to warrant appropriate and defensible conclusions about the phenomenon under investigation such as online teaching and learning during a pandemic.

\section{Keywords}

Online Learning, Research Instrument, Reliability, Validity

\section{Introduction}

Reliable and valid research instruments are needed in the research data gathering and would make possible truthful conclusions about the people and phenomenon of interest (Fraenkel \& Wallen, 2008; Best \& Kahn, 2003) such as the prevailing worldwide pandemic phenomenon. Published articles utilized various research instruments like survey questionnaires that are readily available and accessible online but provide insufficient information regarding the technical adequacy of the instruments. In education, survey results and findings during health-related crises become imperative to inform educational policy-making and decisions, thus, research instrumentation must be an important consideration. The dearth of reliability and validity-related evidence of research instruments used in capturing students' perceptions of their online teachers during a pandemic may result in dubious conjectures and inappropriate inferences.

Students' expectations of their teachers during a pandemic were intensified and urgent with the entire online learning that is generally a novel experience for most of them. These include the teacher's characteristics as being extra considerate, understanding, kind, attending to their needs during online classroom synchronous and asynchronous sessions. Communication is essential through various modes such as phone calls, text messaging, emails, and video or audio chats. These expectations cannot be measured directly but students could express through the accomplishment of an online questionnaire which the information could be the basis for instrument reliability and validity. This study provides substantial information regarding the development of research instruments that would be useful in educational research during the pandemic. 


\section{Literature Review}

Several local reports and studies regarding education during the pandemic include problems in online classes (Amadora, 2020), acting on remote learning problems (Adonis, 2021, Philippine Daily Inquirer), the challenges and expectations among students in entirely online learning (Belgica et al., 2020; Francisco \& Barcelona, 2020). Similar reports that are accessible online showed how pandemics impact the education sector where the learners are mostly affected (United Nations, 2020; Covid-19 and Education, 2020; UNESCO, 2020). Providing authentic learning experiences among students is among the potential opportunities for improvement in educational settings (Deslandes-Martineau, et al., UNESCO 2020). The researcher found a limited study that described the technical adequacy of the instruments used in capturing students' perceptions of their online teachers during a pandemic.

Sound research instruments with technical adequacy such as reliability and validity generate adequate and appropriate conclusions about opinions, beliefs, concerns, and sentiments of people concerning the pandemic experience. Surveys reported substantial information regarding online teachers' characteristics, qualities, and communication that facilitate online teaching and learning. These include teachers as the patient, empathetic, adaptable, passionate in teaching the subject, learners-focused, creating a culture of engaging and creative virtual classroom, and ensuring connectedness (Top qualities of a good teacher, 2020; Shriner, 2015; Waldeck et al., 2020; Norell, 2020; Nemo, 2020; Boudreau, 2020; Cross, 2020). Further analysis of this information and subsequent inferences are beneficial to policy-making and educational decisions. This is made possible with the use of a reliable instrument that yields dependable results about the construct measured regarding the individuals. A valid instrument guarantees defensible, truthful, accurate inferences and predictions about individuals which is the primary purpose of educational and psychological testing (Fraenkel \& Wallen, 2008; Best \& Kahn, 2003; Phelps, 2009). Contentrelated validity is evident in the instrument when the items measure the intended traits (Best $\&$ Kahn, 2003). Construct validity can be assessed statistically through factor analysis that scrutinizes the test items, determines correlated and clustered variables signifying latent factor, and reduces the number of variables yet measuring the same traits (Fraenkel \& Wallen, 2008; Phelps, 2009; Best \& Kahn, 2003; Mertens, 2005). Instrument usability comprises a facility for administration and scoring, non-discriminatory to intended individuals or examinees, and providing evidence of established reliability and validity (Fraenkel \& Wallen, 2008). 
Reliability and validity of research instrument is important as determined with the use of Cronbach's alpha for internal consistency and exploratory factor analysis in determining the underlying dimensions of the instrument (Freedman, 2010; Lacko et al, 2010; Laurie \& Sloat, 2016; Leek \& Robitaille, 2011; Heatherton \& Polivy, 1991; Tuerlinckx et al, 2002). Selection and experts' reviews are deemed important besides statistical analyses to guarantee the appropriateness of the instrument (Alhadabi \& Aldhafri, 2021; Braunsberger \& Gates, 2009; Shrivashav et al, 2005). The design of the instrument facilitated the scoring and contributed to its usability.

\section{Methods and Procedures}

This mixed-methods study used exploratory sequential that considered a few open-ended questions about online learning to create a meaningful scale and encourage increased participation in the online survey. Likert-type scale items were formulated from the responses to the open-ended questions that asked the students to describe their online teacher based on actual observations. Open-ended questions were sent via email to students who voluntarily emailed back their responses. Ethical considerations were observed like confidentiality and anonymity of response source, and deletion of email addresses once the responses were encoded. Variables that were assumed to influence online learning like technology literacy, internet connectivity, and availability of computer devices and programs were controlled in the study, thus excluding those participants who did not satisfy the above criteria for inclusion. The aggregated responses were reviewed to generate the final 33 items that were strictly for research purposes only.

Students enrolled in the academic year 2020-2021 through teachers, parents, and costudents' referrals were invited to answer the online questionnaire sent via email. Participation in the survey was strictly voluntary and the students were instructed to email back the accomplished survey instrument within a month upon receipt of the email. Voluntary participation was satisfactory with a total of 1,508 response rate. No identifying information was associated with the returned questionnaire except for the email addresses that were discarded right away after data collection. No follow-up with the participants was undertaken regarding the missing information like age, gender, school type, and grade level, thus missing information was not included in the analysis. The summated scores from Likert-type items reflect the ratings of the way the students have observed the online teacher during the synchronous and asynchronous distance online learning. 
Data presented in Table 1 came from the participants who volunteered to share the necessary information. These included the proportion according to grade levels such as $46 \%$ firstyear college, $28 \%$ senior secondary, $26 \%$ junior secondary, composition of female students (63\%) and male students (37\%), and according to school type (public schools, 56\%; private schools, $44 \%)$.

Table 1: Participants' Demographic Information

\begin{tabular}{lcc}
\hline Information & $\mathrm{N}$ & $\%$ \\
\hline Grade/Year Level & & \\
Junior Secondary & 386 & 26 \\
Senior Secondary & 427 & 28 \\
College First Year & 695 & 46 \\
Gender & & \\
Female & 949 & 63 \\
Male & 559 & 37 \\
School Type & & \\
Private & 658 & 44 \\
Public & 850 & 56 \\
\hline
\end{tabular}

(Source: Self)

\subsection{Instrument Psychometric Analyses}

The stability of the items and internal consistency in each subscale were determined. The overall and item alpha was reviewed. Ambiguous and inconsistent items were deleted. Evidence for content validity consisted of the judgmental reviews and instrument experts' suggestions to include the items that measure the intended constructs and traits. Construct validity-related evidence was statistically determined through subjecting the dataset to exploratory factor analysis using principal component analysis to identify the cluster of variables. A factor loading of .40 was considered and suggested in Field (2000, 2009). Item qualitative reviews were undertaken before and after examining the results of the statistical analyses. Comparative analyses of the responses across groups and subscales were done subsequently.

\section{Results}

The statistics results and the instrument development experts' suggestions were the bases in the finalization of the three subscales and the corresponding number of items which were determined after the data reduction process using the principal component analysis (PCA). The overall reliability of the 33 items is excellent (alpha $=.956)$. The deletion of any items would lower 
the instrument's overall Cronbach alpha, therefore not recommended. Table 2 shows the subscales' reliability information. The data were collected from the participants' summated scores in the research instrument. The Cronbach's alphas are consistently high in subscale 1 (.928) and subscale 2 (.910). In subscale 3, Cronbach's alpha (.689) is acceptable. The summated scoring generated scores for each student that reflect agreement on the number of statements about teachers' observable characteristics and behaviors during the online instruction and monitoring. Higher scores in subscale 1 correspond to a higher agreement that positive personality traits and characteristics of the online teacher during the pandemic are evident and observable. Classroom management skills and behavior of the teacher during the online synchronous classroom cater and tailor-fit to the needs of the students when the scores are high in subscale 2. The teacher's mode of communication and connectedness during the pandemic are responsive to the needs of the students with a high score in subscale 3 . The average scores in the subscales are considered high.

Table 2: Descriptive Statistics and Reliability in the Subscales

\begin{tabular}{llll}
\hline \multicolumn{1}{c}{ Statistics } & \multicolumn{1}{c}{$\begin{array}{c}\text { Subscale 1 Personal } \\
\text { Traits \& } \\
\text { Characteristics }\end{array}$} & $\begin{array}{c}\text { Subscale 2 Classroom } \\
\text { Management Skills \& } \\
\text { Behavior }\end{array}$ & $\begin{array}{c}\text { Subscale 3 } \\
\text { Communication \& } \\
\text { Connectedness }\end{array}$ \\
\hline Number of Items & 12 & 13 & 5 \\
X (Mean) & 39.93 & 42.45 & 14.74 \\
SD & 6.31 & 6.62 & 2.96 \\
Potential Range & $12-48$ & $13-52$ & $5-20$ \\
Actual Range & $16-48$ & $13-52$ & $5-20$ \\
Cronbach Alpha & .928 & .910 & .689 \\
\hline
\end{tabular}

(Source: Self)

\subsection{Principal Component Analysis}

Before subjecting the 33 items to PCA, the data were first assessed for suitability for the analysis using Kaiser-Meyer-Olkin and Bartlett's test. KMO statistic value of .971 is considered excellent, and Bartlett's test value is less than .005 supporting the factorability of the variables and appropriateness of the dataset to PCA. Before extraction, the dataset's linear components were identified. Findings show that the values of the 33 components were all 1.000 before extraction, while after extraction, the percentage of the variance associated with a particular item indicates the common or shared variance. There were four factors extracted. Factor 1 accounts for $46.184 \%$ of the total variance. Examining closely the factor loading, three items under factor four also loaded in factors 1 and 2, thus reducing the factors into three upon test experts' suggestions. Factor loadings of .40 and greater were considered in the study that represents substantive values (Steven, 
2002, mentioned in Field, 2009). Table 3 shows the loadings on the three factors. The data source was the participants' scores in the individual items in the research instrument that were organized in the spreadsheet.

Table 3: Factor Structure of the My Online Teacher during a Pandemic Scale

\begin{tabular}{|c|c|c|c|}
\hline Scale Items & $\begin{array}{l}\text { Factor 1: } \\
\text { Personal Traits } \\
\quad \& \\
\text { Characteristics }\end{array}$ & $\begin{array}{c}\text { Factor 2: } \\
\text { Classroom } \\
\text { Management } \\
\text { Skills \& Behavior }\end{array}$ & $\begin{array}{c}\text { Factor 3: } \\
\text { Communication } \\
\text { \& Connectedness }\end{array}$ \\
\hline 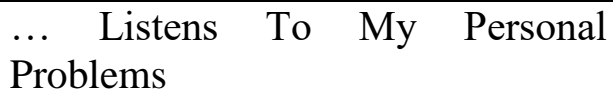 & 0.845 & & \\
\hline ... Listens To My Family Problems & 0.844 & & \\
\hline ... Respects My Ability & 0.732 & & \\
\hline $\begin{array}{l}\text {.. Helps Me Understand The } \\
\text { Lesson }\end{array}$ & 0.724 & & \\
\hline $\begin{array}{l}\text {.. Understands When I Cannot } \\
\text { Attend Synchronous Class Sessions }\end{array}$ & 0.715 & & \\
\hline $\begin{array}{l}\text {... Gives Sincere/Honest Advice } \\
\text { And Feedback On My School } \\
\text { Works }\end{array}$ & 0.704 & & \\
\hline $\begin{array}{l}\text {... Is Gentle In Action } \\
\text {... Encourages Me To Showcase } \\
\text { My Good/Best Performance In The } \\
\text { Subject/Course }\end{array}$ & $\begin{array}{l}0.695 \\
0.695\end{array}$ & & \\
\hline $\begin{array}{l}\text {.. Is Gentle In Words } \\
\ldots \quad \text { Recognizes My Good } \\
\text { Performance In Class }\end{array}$ & $\begin{array}{l}0.687 \\
0.648\end{array}$ & & \\
\hline $\begin{array}{l}\text {.. Listens To My Internet/Wi-Fi } \\
\text { Problems }\end{array}$ & 0.641 & & \\
\hline $\begin{array}{l}\text { Listens To My Academic } \\
\text { Problems }\end{array}$ & 0.560 & & \\
\hline $\begin{array}{l}\text {...Shows Concern When I Am } \\
\text { Having Difficulty Accomplishing } \\
\text { Modular Exercises }\end{array}$ & & 0.776 & \\
\hline $\begin{array}{l}\text {...Knows When I Am Having } \\
\text { Trouble Adjusting To An Online } \\
\text { Classroom }\end{array}$ & & 0.767 & \\
\hline $\begin{array}{l}\text {...Responds To My Questions And } \\
\text { Queries Regarding The Lessons \& } \\
\text { Discussion }\end{array}$ & & 0.749 & \\
\hline $\begin{array}{l}\text {...Responds Right Away To My } \\
\text { Questions With Clear Answers And } \\
\text { Explanation }\end{array}$ & & 0.722 & \\
\hline
\end{tabular}




\begin{tabular}{|c|c|c|}
\hline ...Reaches Out And Follow-Up On & 0.702 & \\
\hline Me When I Don't Talk And & & \\
\hline Participate In Class Discussion & & \\
\hline ...Helps Me Identify Problems & 0.698 & \\
\hline Areas In My Study & & \\
\hline ...Addresses My Questions & 0.686 & \\
\hline Sufficiently And Efficiently & & \\
\hline ...Encourages My Participation In & 0.682 & \\
\hline Class Discussion & & \\
\hline ...Provides Negative But & 0.679 & \\
\hline Encouraging Feedback On My & & \\
\hline Works And Class Participation & & \\
\hline ...Provides Positive Feedback On & 0.664 & \\
\hline My Works And Class Participation & & \\
\hline ... Does Not Reprimand Late & 0.636 & \\
\hline Submission Of Assignments And & & \\
\hline Homework & & \\
\hline ... Is Fair And No Favorites In & 0.609 & \\
\hline Calling Students During An Online & & \\
\hline Real-Time Class Session & & \\
\hline ...Calls The Attention Of Students & 0.497 & \\
\hline Making Unnecessary Noise And & & \\
\hline Distractions During An Online & & \\
\hline Real-Time Class Session & & \\
\hline ... Communicates Through Phone & & 0.802 \\
\hline Calls For Real-Time Instruction & & \\
\hline When I Need It & & \\
\hline ... Communicates Through Text & & 0.715 \\
\hline Messaging To Help Me Cope With & & \\
\hline Online Learning & & \\
\hline ... Entertains Right Away And & & 0.678 \\
\hline Promptly My Phone Calls And Text & & \\
\hline Messages & & \\
\hline ... Communicates Through Daily & & 0.560 \\
\hline Exchanges Of Emails With Me & & \\
\hline $\begin{array}{l}\text {... Communicates Through Video } \\
\text { Chat }\end{array}$ & & 0.538 \\
\hline
\end{tabular}

(Source: Self)

Three items with factor loadings less than .40 were not included in the final form of the instrument thus reducing the number of items from 33 to 30. Instrument development experts' reviews and informed suggestions finalized the theme for each factor.

Examining closely the items' contents under factor 1, the students observed that the personal traits and characteristics of their effective online teacher include being understanding and 
listening actively to their concerns and problems in online learning whether personal and familyrelated, lesson-related, technology, and internet connections-related. The participants claimed stable internet access. However, there were inevitable internet problems during a pandemic because of the high demand for Wi-Fi as everyone is working from home. Intermittent internet connections affected students' compliance with submission deadlines for class assignments and paper works. Teachers' support and understanding help the students cope with the academic requirements. Likewise, gentleness and compassion encouraged and motivated the students to strive for better to best performance in the course. Research reveals that effective online teachers are patient, empathetic, and adaptable (Top qualities of a good teacher, 2020), show passion in teaching, invite feedback from students, and promote an engaging and creative classroom (Shriner, 2015). The crucial role of the instructor persona (Waldeck et al., 2020) is important in teaching and learning and has a clear focus on students' needs (Norell, 2020). Teachers need to ensure that students are coping well with the transition during a pandemic; letting the students know that their teacher is there to support them (Nemo, 2020).

Items under factor 2 pertain to classroom management skills and behavior. Students believed that teachers must be sensitive to individual concerns of the students, especially during the synchronous class session. They expected their teacher to show concern when they were having difficulty accomplishing modular exercises, adjusting to the online classroom, and responding promptly to their queries during class discussions. Further, they were motivated when the teacher showed fairness in dealing with students, encouraged active participation during real-time online classes, and was sensitive enough when just a few students could catch up with the lesson and class discussion. Encouraging feedback on class works motivates students to participate actively during the real-time virtual classroom. Students appreciated the virtual classroom atmosphere when teachers refrained from reprimanding late submission of assignments and gently called the attention of students who were making unnecessary noise and distractions during the online session. Research shows that students can feel their teachers' enthusiasm for the subject matter through live, exciting, and engaging online lessons and interaction, providing quick and efficient assistance as subject matter experts, and recognizing every student's unique needs (Connections Academy, 2020). Teachers need to create and foster a culture of belongingness, independence, connectedness, engagement, and power dynamics among students in a virtual classroom (Boudreau, 2020; Cross, 2020). 
Factor 3 points explicitly to communication and connectedness. Students expressed high expectations from online teachers during the pandemic, to connect and communicate with them either through emails, text messaging, but preferably real-time instruction through phone calls and video chat to help them cope with the lessons. Teachers need to find ways to reach out to students who feel alone and deserted in a digital classroom (Cooper, 2016). Amidst evolving technology, online teachers are expected to be tech-savvy and comfortable with recent online learning tools (Connections Academy, 2020). Teachers checking in the students might be more direct, with oneon-one chats or regular email updates, determining how students are doing, and tailoring information or assignments based on how everyone is progressing (Ferdig, as mentioned in Nemo, 2020). Nemo further mentioned that teachers should be clear about how students can come up to them with questions, when and how, the time to send emails, and expect a response.

\subsection{Comparing Scores in the Subscales Across Groups}

The three factors or dimensions that emerged from the PCA are considered subscales of the developed instrument. The potential range of scores was derived from the highest possible and lowest possible scores concerning the number of items in the subscale. The actual range of scores pertains to the highest and lowest scores of the students on the subscale. The scores reflect the ratings the way the students have observed the online teacher. The higher the scores on the subscale, the higher the agreement that the item is true and observable of the online teacher.

Table 4: Scores in the Subscales

\begin{tabular}{llll}
\hline \multicolumn{1}{c}{ Variable } & \multicolumn{1}{c}{$\begin{array}{c}\text { Subscale 1 } \\
\text { Personal Traits } \\
\text { \& Characteristics }\end{array}$} & $\begin{array}{c}\text { Subscale 2 } \\
\text { Classroom } \\
\text { Management Skills } \\
\text { \& Behavior }\end{array}$ & $\begin{array}{c}\text { Subscale 3 } \\
\text { Communication \& } \\
\text { Connectedness }\end{array}$ \\
\hline $\begin{array}{l}\text { Number of Items } \\
\text { Mean Score }\end{array}$ & 12 & 13 & 5 \\
$\quad$ College First Year & 38.13 & 40.69 & 14.17 \\
$\quad$ Senior Secondary & 42.35 & 44.90 & 15.21 \\
$\quad$ Junior Secondary & 40.59 & 43.19 & 15.10 \\
SD & & & 2.82 \\
College First Year & 6.20 & 6.39 & 3.44 \\
$\quad$ Senior Secondary & 5.88 & 6.63 & 2.76 \\
$\quad$ Junior Secondary & 6.25 & 6.51 & $5-20$ \\
Potential Range & $12-48$ & $13-52$ & $5-20$ \\
Actual Range & & $13-52$ & $5-20$ \\
$\quad$ College First Year & $16-48$ & $14-52$ & $7-20$ \\
$\quad$ Senior Secondary & $17-48$ & $21-52$ & \\
$\quad$ Junior Secondary & $17-48$ & & \\
\hline
\end{tabular}




\section{(Source: Self)}

Table 4 presents the descriptive statistics in the subscales. The data were computed from the participants' summated scores in the research instrument. The senior secondary students showed a very high average in subscale 1 , followed by the junior secondary and college students. Although the average score of the college students is lower than the other groups, it is still considered high. This finding is also true in subscale 2 which the senior high school students rated the online teacher higher in terms of classroom management skills and behavior compared to junior high school and college students. Regarding subscale 3, the junior and senior high school students rated their online teachers higher that help them learn and succeed in online learning, while the college students perceived communication and connectedness of online teachers as just average. Almost similar spreading of scores around the mean is apparent in subscale 2, but a slight difference in subscales 1 and 3.

Before conducting the ANOVA to compare the scores of the groups in the subscales, the Levene statistics tested the homogeneity of the variances. For the dataset, Levene statistic is .065 in subscale $1(\mathrm{p}>.05), .194$ in subscale $2(\mathrm{p}>.05)$, and .060 in subscale $3(\mathrm{p}>.05)$, that satisfied the assumption required of ANOVA.

ANOVA results reveal significant differences among the scores of the three groups about their online teacher during a pandemic. The finding is true in the three subscales with the following F statistics values $(2,1505)=65.376,54.243$, and 25.799, respectively; p-values are $.000(\mathrm{p}<$ 0.05). Further comparative analysis was carried out using the Bonferroni post hoc test to explore between-group differences. In the study, three comparisons were undertaken, i.e., college vs senior secondary vs junior secondary. Results show that the three groups were significantly different in rating the online teacher in terms of personal traits and characteristics (subscale 1) and classroom management skills and behavior (subscale 2). The reverse was true regarding online teacher communication mode and establishing connectedness, which the two groups - junior and senior secondary students' ratings were not significantly different; the college students remained significantly different from the other groups. Noteworthy was the senior secondary students leaning on their earlier learning experiences and expectations in junior secondary. Their scores were not significantly different compared to junior secondary students' expectations of their online teachers' manners and approaches in staying connected in an entirely remote online learning during a pandemic. The college students were significantly different from the senior and junior 
secondary students' ratings of the online teacher communication and connectedness in entirely online learning during a pandemic.

\subsection{Comparing Students in the Public and Private Schools}

There is a higher proportion of students from the public (56\%) than private (44\%) who volunteered to participate in the study. The data presented in Table 5 came from the actual scores of the two groups in the subscales that pertain to the level of agreement regarding the items in the instruments.

Table 5: Comparing Students from Public and Private Schools in the Subscales

\begin{tabular}{llll}
\hline \multicolumn{1}{c}{ Variable } & \multicolumn{1}{c}{$\begin{array}{c}\text { Subscale 1 } \\
\text { Personal Traits } \\
\text { \& Characteristics }\end{array}$} & $\begin{array}{c}\text { Subscale 2 } \\
\text { Classroom } \\
\text { Management, Skills } \\
\text { \& Behavior }\end{array}$ & $\begin{array}{c}\text { Subscale 3 } \\
\text { Communication \& } \\
\text { Connectedness }\end{array}$ \\
\hline Number of Items & 12 & 13 & 5 \\
Mean Score: Public & 39.68 & 42.02 & 14.82 \\
Mean Score: Private & 40.27 & 43.00 & 14.64 \\
SD: Public & 6.08 & 6.36 & 2.82 \\
SD: Private & 6.58 & 6.91 & 3.12 \\
p-value & $.074(\mathrm{p}>.05)$ & $.005(\mathrm{p}<.05)$ & $.239(\mathrm{p}>.05)$ \\
\hline
\end{tabular}
(Source: Self)

Table 5 shows that the students in the public and private schools are not significantly different as regards their ratings of their online teachers' traits and characteristics during the pandemic, the two-tailed p-value associated with the t-statistic is greater than $0.05(\mathrm{p}=.074)$. As earlier mentioned, a teacher's traits and characteristics include being understanding and listening to students' problems not only related to class lessons and discussions but to personal and family concerns as well. Both students in the public and private schools observed the gentleness and compassion of their teacher that encouraged, motivated, and inspired them to strive for better to best performance in the course.

The same finding is evident in subscale 3 (communication and connectedness) which the two-tailed $p$-value associated with the t-statistic is greater than $0.05(\mathrm{p}=0.239>0.05)$; therefore, no significant difference between students' ratings the online teachers regarding communication and connectedness during the pandemic. Students in the public and private schools observed their online teachers as efficient enough who tried to connect and communicate with them through emails, text messaging, and phone calls for real-time instruction and whenever they need to ask questions regarding the lessons; to help them cope and survive the entirely online learning. 
Opposite results are observed in subscale 2 which the p-value associated with the t-statistic $(\mathrm{p}=0.005)$ is less than 0.05 showing a significant difference between the public and private students' scores or ratings as regards classroom management skills and behavior of the online teacher. The private schools' students' mean score is significantly higher than the counterpart public schools; the mean difference is statistically significant. The ratings of the students were based on their observations and actual experiences in the virtual classroom as regards teachers' online classroom management skills and behavior. Items under factor 2 pertain to how the teacher manages the online classroom and the behavior, performance, and manners in conducting the realtime online synchronous classes. Students expect the teacher to be sensitive to their concerns like when they are having difficulty understanding the teacher's presentation to help them accomplish modular exercises, adjusting to the online classroom, and coping with the lessons and discussion. Students expect the teacher to respond readily and promptly to their queries during class discussions. They are motivated by the teacher's fair treatment, giving each student the chance to ask a question, to participate, and is sensitive to those who could not catch up with the lesson and class discussion, and providing positive and negative but encouraging feedback on class works. The teacher's extra compassion and understanding in the online classroom are evident when not reprimanding late submission of assignments and homework, and gently calling the attention of students making unnecessary noise and distractions during the online session.

\subsection{Comparing Female and Male Students}

There were more female students (63\%) than male students $(37 \%)$ who volunteered to participate in the online survey. Data presented in Table 6 came from the actual summated scores of the participants in the research instrument. The mean scores reflect the ratings as regards personal traits and characteristics, classroom management skills and behavior, and establishing communication and connectedness in the entirely remote online learning. The actual range of scores varies between groups across the subscales. In subscales 1 and 2, the range of scores is low to very high for male students while very low to very high for female students. In subscale 3 , the range of scores is very low to very high for both male and female students.

Table 6: Comparing Male and Female Students in the Subscales

\begin{tabular}{cccc}
\hline Variable & $\begin{array}{c}\text { Subscale 1 Personal } \\
\text { Traits \& } \\
\text { Characteristics }\end{array}$ & $\begin{array}{c}\text { Subscale 2 Classroom } \\
\text { Management, Skills } \\
\text { \& Behavior }\end{array}$ & $\begin{array}{c}\text { Subscale 3 } \\
\text { Communication \& } \\
\text { Connectedness }\end{array}$ \\
\hline Number of Items & 12 & 13 & 5 \\
\hline
\end{tabular}




\begin{tabular}{llll}
\hline Mean Score: Male & 40.58 & 43.06 & 15.10 \\
Mean Score: Female & 39.55 & 42.09 & 14.52 \\
SD: Male & 5.74 & 6.19 & 2.95 \\
SD: Female & 6.59 & 6.84 & 2.94 \\
p-value & $.003(\mathrm{p}<.05)$ & $.000(\mathrm{p}<.05)$ & $.000(\mathrm{p}<.05)$ \\
\hline
\end{tabular}

(Source: Self)

Examining the mean scores across the subscales, table 6 shows that the male students provided consistently higher ratings than female students as regards the online teacher's traits and characteristics, classroom management skills and behavior, and establishing communication and connectedness during the pandemic. The scores are more dispersed among female students in subscales 1 and 2. The independent t-test results show a significant difference between groups across the three subscales, p-values are less than 0.05. Despite that, both groups observed the positive personal traits and characteristics of the online teacher, the ratings of the male students are significantly higher than the female students. Similar findings hold as regards classroom management skills and behavior of the online teacher and in the area of establishing communication and connectedness during the pandemic entirely online learning. It is interesting to note that students whether male or female observed the positive traits of the online teacher during the pandemic as sensitive to their needs, understanding their problems in online learning, and those family and personal-related concerns. Further, both groups of students experienced the teacher's compassion and understanding when they were not able to beat deadlines for the course and subject requirements and paper works due to inevitable intermittent internet connections and personal problems. Online classroom teachers' management skills involve discipline and exercising fairness that motivates students to learn and participate actively during real-time online classes. Students reported that their online teachers were providing positive feedback for good performance and encouraging feedback to those underperforming and non-performing students. Communication and connectedness between the online teacher and the students promote survival in entirely online learning. The male and female students agreed that their online teachers utilized various modes of communication to stay connected, through emails, text messaging, and real-time instruction through phone calls and video chat to help them cope with the lessons. 


\section{Conclusion and Discussion}

Research findings during the pandemic bridged more research, but it is deemed helpful for researchers to include in their reports the psychometric evidence of any research instrument to warrant accurate conclusions regarding the phenomenon under investigation. Research and reports that proliferated and shared on the internet provide useful information like the educational crisis in more than a hundred countries has worsened because of pandemic (United Nations, 2020). A significant number of learners are affected worldwide (Education International, 2020), including its impact on the higher education sector (Covid-19 and Education, 2020). Local reports pointed out the problems related to entirely online classes and remote learning (Adonis, 2021). Limited research discussed the reliability and validity of any research instruments utilized in the study.

In this study, inviting students to participate in the survey elicited a positive response. The 33-item Likert-type survey instrument was administered to the junior and senior secondary students, and to college freshmen who volunteered to accomplish the online survey. Findings show that the instrument internal consistency is generally high except in subscale 3 which is acceptable. Content validity-related evidence of the instrument was judged through expert reviews, and construct validity was assessed statistically using principal component analysis. The results of the PCA and expert reviews finalized the three factors called the subscales. These are personal traits and characteristics, classroom management skills and behavior, and communication and connectedness. Summated scores reflect the ratings of the students of their online teachers during the synchronous and asynchronous distance online learning. Comparative analysis of the mean scores between and among groups across the subscales was determined using the independent $\mathrm{t}$ test and one-way ANOVA, respectively.

ANOVA results reveal significant differences among the three groups of students regarding their observations of their online teachers during a pandemic as reflected on the mean scores. The post hoc tests' results show that the three groups were significantly different in rating the online teacher in subscales 1 and 2. In subscale 3, the junior and senior secondary students' ratings were not significantly different, but the college students remained significantly different from the other groups. Senior and junior secondary students' ratings were not significantly different as regards their online teachers' connectedness and communication during a pandemic.

Students in the public and private schools expressed similar observations of their online teachers as reflected in their responses to the scale, specifically on subscales 1 and 3. Positive 
personal traits and characteristics of their teacher like gentleness and compassion encouraged, motivated, and inspired them to survive online learning. The mode of communication and connectedness was through emails, text messaging, and phone calls for real-time instruction and whenever the students need to ask questions regarding the lessons. However, findings show a significant difference between the public and private students' scores on subscale 2, their ratings as regards classroom management skills and behavior of the online teacher. The students considered important how the teacher managed and conducted the real-time online synchronous classes. These include being sensitive to their concerns like difficulty understanding the teacher's presentation, lessons, and discussion, ready and prompt response to queries or questions, sensitive to those who could not catch up with the lesson and discussion, providing encouraging feedback on class works, and not reprimanding late submission of assignments and course works.

Male and female students were significantly different as regards their observations of the online teacher which the male students' ratings were significantly higher than the female students in the areas of teacher's classroom management skills and behavior, and establishing communication and connectedness during the pandemic entirely online learning. Statistically, the significant mean difference was influenced by the group's variance, as equal variances were not assumed in the subscales.

The students' expectations of their teacher during a pandemic could differ across grade levels, between male and female students in the public and private schools. A scale that focuses on entirely online teaching could capture the picture of the discrepancy between students' observations and their expectations. The survey instrument with its psychometric evidence developed in this study intends to contribute to the existing pool of useful information related to a pandemic. This may be utilized to further the usability of the instrument, to guarantee appropriateness and accuracy of any research finding, the inferences about the phenomenon under an investigation like education during a pandemic. Related research may address the limitation of this study such as including a representative sample across school culture and environment, considering cross-case analysis, and the use of sophisticated psychometric analysis in instrument development. 


\section{REFERENCES}

Adonis, M. (2021). PH lags behind in acting on remote learning problems amid pandemics. Philippine Daily Inquirer. https://newsinfo.inquirer.net/1418185/ph-lags-behind-inacting-on-remote-learning-problems-amid-pandemic

Alhadabi, A., \& Aldhafri, S. (2021). A Rasch model analysis of the psychometric properties of the student-teacher relationship scale among middle school students. European Journal of Educational Research. 10(2), 957 - 973.

Amadora, M. (2020). Common problems that occur during online classes. Manila Bulletin, Technology News. https://mb.com.ph/2020/09/18/common-problems-that-occur-duringonline-classes/https://mb.com.ph/2020/09/18/common-problems-that-occur-duringonline-classes/

Belgica, C.C., Calugan, J.A., Dumo, J.U., \& Simber, L. A. (2020). Online distance learning: Thematic study on the challenges faced by Educare College Inc. primary pupils. $3^{\text {rd }}$ international conference on advanced research in education, teaching \& learning. https://www.dpublication.com/wp-content/uploads/2020/12/30-10340.pdf

Best, J. and Kahn, J. (2003). Research in Education (9th ed.). USA: Pearson Education, Inc.

Boudreau, E. (2020). What makes an excellent online teacher? Strong decision-making skills can help educators build engaging and welcoming virtual classrooms. https://www.gse.harvard.edu/news/uk/20/07/what-makes-excellent-online-teacher

Braunsberger, K., \& Gates R. (2009). Developing inventories for satisfaction and Likert scales in a service environment. Journal of Services Marketing. 23(4), 219 - 225.

Connections Academy (2020). Skills that make a great online school teacher. https://www.connectionsacademy.com/support/resources/article/9-skills-that-make-greatonline-school-teacher

Cooper, S. (2016). 10 Best Practices to be an effective online teacher. Retrieved from https://elearningindustry.com/10-best-practices-effective-online-teacher COVID-19 and Education: How Education Unions are Responding (A Survey Report) 2020).

Brussels: Education International.

https://issuu.com/educationinternational/docs/2020_covid19_survey_report_eng_final

Cross, T. (2020). Six ways to improve your online teaching. Teaching and Education. 
https://www.wgu.edu/blog/6-ways-improve-your-online-teaching2003.html\#close

Deslandes-Martineau, M. et al. (2020). Education and COVID-19: Challenges and opportunities: Canadian Commission for UNESCO. https://en.ccunesco.ca/idealab/education-and-covid19-challenges-and-opportunities

Field, A. (2000). Discovering Statistics Using SPSS for Windows. SAGE Publications, Inc.

Field, A. (2009). Discovering Statistics Using SPSS (3rd ed.). SAGE Publications, Inc.

Fraenkel, J., \& Wallen, N. (2008). How to Design and Evaluate Research in Education (7th ed.). McGraw-Hill Companies, Inc.

Francisco, C., \& Marites B. (2020). Effectiveness of an online classroom for flexible learning. International Journal of Academic Multidisciplinary Research. 4(8), 100 - 107. https://files.eric.ed.gov/fulltext/ED607990.pdf

Freedman, M. R. (2010). Development, evaluation, and validation of environmental assessment tools to evaluate the college nutrition environment. Journal of American College Health. $58(6), 565-568$.

Heatherton, T. F., \& Polivy, J. (1991). Development and validation of a scale for measuring state self-esteem. Journal of Personality and Social Psychology. 60(6), 895 - 910.

Lacko, S. R., Little, K., Meltzer, H., Rose, D., Rhydderch, D., Henderson, C., \& Thornnicroft, G. (2010). Development and psychometric properties of the mental health knowledge schedule. Canadian Journal of Psychiatry. 55(7), 440 - 448.

Laurie, R., \& Sloat, E. (2016). Investigating key psychometric properties of the French version Of the early years' evaluation-teacher assessment. Canadian Journal of Education. 39(3), $1-24$.

Leek, J. D., \& Robitaille, A. (2011). Psychometric properties of the behavioral trust inventory for measuring trust in mentoring relationships. The Journal of American Academy of Business, Cambridge. 17(1), 119 - 124.

Mertens, D. (2005). Research and Evaluation in Education and Psychology: Integrating Diversity with Quantitative, Qualitative, and Mixed Methods (2nd ed.). SAGE Publications, Inc.

Nemo, L. (2020). What decades of research tell us about student success in the online classroom? 
https://www.discovermagazine.com/mind/what-decades-of-research-tells-us-aboutstudent-success-in-the-online

Norell, L. (2020). Stop Blaming Students! Why We Must Teach Students, Not Content, The Best of the 2020 Teaching Professor Conference. Retrieved from https://www.magnapubs.com/wp-content/uploads/2021/02/Best-of-TPC-2020.pdf

Phelps, R. P. (2009). Correcting Fallacies about Educational and Psychological Testing. American Psychological Association.

Shriner, B. (2015). Seven characteristics of effective online teachers. https://adjunctworld.com/blog/7-characteristics-of-effective-online-teachers

Shrivashav, R., Sapienza, C. M., \& Nandur, V. (2005). Application of psychometric theory to the Measurement of voice quality using rating scales. Journal of Speech, Language, and Hearing Research. 48(2), 323 - 335.

Top qualities of a good teacher (2020).

https://www.wgu.edu/blog/top-qualities-skills-good-teacher2001.html

Tuerlinckx, F., De Boeck, P., \& Lens, W. (2002). Measuring needs with the thematic Apperception test: A psychometric study. Journal of Personality and Social Psychology. $82(3), 448-461$.

UNESCO IESALC. (2020). Covid-19 and Higher Education: Today and Tomorrow Impact Analysis, Policy Responses and Recommendations. http://www.iesalc.unesco.org/en/wpcontent/uploads/2020/04/COVID-19-EN-090420-2.pdf

United Nations. (2020). Policy Brief: Education during COVID-19 and beyond. New York City: United Nations. https://www.un.org/development/desa/dspd/wpcontent/uploads/sites/22/2020/08/sg policy brief covid-19

Waldeck, J. H., Johnson, Z., \& LaBelle, S. (2020). Confidence, Clarity, and Concern: Developing an Effective Teaching Persona, The best of the 2020 Teaching Professor Conference. https://www.magnapubs.com/wp-content/uploads/2021/02/Best-of-TPC2020.pdf 